\title{
Landesversammlung Niedersachsen
}

\section{Hier steht eine Anzeige.}

Ort:

Parkhotel Luisenhöhe, Am Vogelpark 2, 29699 Bomlitz/Walsrode Termin:

Samstag, 18. Juni 2016, Beginn: $10.00 \mathrm{Uhr}$

\section{Tagesordnung}

1. Begrüßung, Eröffnung, Feststellung der Beschlussfähigkeit, Totenehrung

2. Fragestunde

(Die Fragen dürfen sich nicht auf Punkte der Tagesordnung beziehen, sollen kurz und klar gefasst sein und müssen mindestens eine Woche vor der Sitzung der Landesversammlung in der Landesgeschäftsstelle schriftlich eingegangen sein.)

3. Gastvortrag: Minister a. D. Walter Hirche, FDP

4. Bericht der Landesvorsitzenden

5. Bericht des Landesgeschäftsführers

6. Bericht des Kassenprüfers

7. Entlastung des Landesvorstandes

8. Genehmigung des Haushaltsplanes 2017

9. Nachwahl eines Kassenprüfers

10. Anträge

(Gemäß $\$ 8$ Abs. 10 der Satzung müssen Anträge, die die Tagesordnung verändern, zwei Wochen vor der Sitzung der Landesversammlung schriftlich bei der Landesgeschäftsstelle eingegangen sein.)

11. Verschiedenes

Die Landesversammlung ist für Mitglieder des Freien Verbandes Deutscher Zahnärzte öffentlich. Rede- und stimmberechtigt sind nur die Delegierten.

Mit kollegialen Grüßen, 